
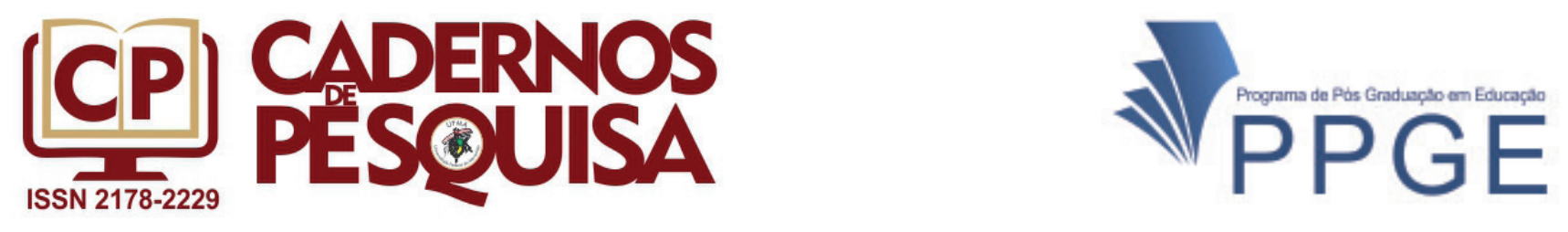

\title{
Análise de conteúdo e seu uso na pesquisa educacional: um estudo em duas escolas da Rede de Educação Profissional Científica e Tecnológica
}

\author{
Analysis of content and its use in educational research: a \\ study in two schools of the Network of Scientific and Technological \\ Professional Education
}

\begin{abstract}
Análisis de contenido y su uso en la investigación educacional: un estudio en dos escuelas de la Red de Educación Profesional Científica y Tecnológica
\end{abstract}

Anselmo Paulo Pires

iD http://orcid.org/0000-0002-0404-8226

Maria Auxiliadora Monteiro Oliveira

iD $h$ ttps://orcid.org/0000-0002-2142-6508

Sandra Fátima Pereira Tosta

iD $h t t p: / / o r c i d . o r g / 0000-0002-4501-1008$

\begin{abstract}
Resumo: Aproximadamente desde os anos de 1980 a pesquisa de natureza qualitativa alcançou larga receptividade no Brasil, objetivandosuperar os limites dos estudos quantitativos, até então predominantes na investigação dos fenômenos sociais. Notadamente, nos campos das Ciências Humanas e Sociais, a opção pela pesquisa qualitativa evidencia os usos de metodologias como o estudo de caso, a história oral, a pesquisa participante, dentre outras. Sendo assim, este artigo tem como objetivo descrever e analisar como a técnica da Análise de Conteúdo foi utilizada em um estudo realizado entre os anos de 2014 a 2017, de acordo com os pressupostos defendidos pela pesquisadora francesa Laurence Bardin. A referência é um estudo realizado com trabalhadores-alunos do ensino noturno em duas escolas da Rede Federal de Educação Profissional, Científica e Tecnológica (RFEPCT). Este artigo se justifica, dentre outras razões, por contribuir para prover o preenchimento de lacunas teóricas e metodológicas no aspecto das análises de dados, dada a carência de produções acadêmicas que se propõem a abordar a temática com o rigor que se faz necessário.
\end{abstract}

Palavras-chave: Análise de Conteúdo. Ensino noturno. Trabalhadores-alunos.

Abstract: Approximately since the 1980s, qualitative research has reached wide acceptance in Brazil, aimingto overcome the limits of the quantitative studies, hitherto predominant in the investigation of social phenomena. Notably, in the fields of Humanand Social Sciences, the option for qualitative research evidences the uses 
of methodologies such as case study, oral history, participant research, among others. Thus, this article aims to describe and analyze how the Content Analysis technique was used in a study conducted between 2014 and 2017, according to the assumptions advocated by the French researcher Laurence Bardin. The reference is a study carried out with student sworking at night in two school softhe Federal Network of Professional, Scientific and Technological Education (RFEPCT). This article is justified, amongotherreasons, by contributing to fill the theoretical and methodological areas in the data analys is aspect, given the lack of academic productions that propose to approach the subject with the necessary rigor.

Keywords: Content Analysis. Night teaching. Worker-students.

Resumen: Aproximadamente desde los años 1980, la investigación de naturaleza cualitativa alcanzó una gran receptividad en Brasil, com el objetivo de superar los límites de los estúdios cuantitativos, hasta entonces, predominantes em la investigación de los fenómenos sociales. En particular, en los campos de las Ciencias Humanas y Sociales, la opción por la investigación cualitativa, evidencia los usos de metodologías como el estudio de caso, la historia oral, la investigación participante, entre otras. Siendo así, este artículo tiene como objetivo describir y analizar cómo la técnica del Análisis de Contenido fue utilizada en un studio realizado entre los años 2014 a 2017, de acuerdo con los presupuestos defendidos por la investigadora francesa Laurence Bardin. La referencia es un studio realizado con trabajadores-alumnos de la enseñanza nocturna en dos escuelas de la Red Federal de Educación Profesional, Científica y Tecnológica (RFEPCT). Este artículo se justifica, entre otras razones, por contribuir para proveer el llenado de lacunas teóricas y metodológicas en el aspecto de los análisis de datos, dada la carencia de producciones académicas que se proponen abordar la temática con el rigor que se hace necesario.

Palabras clave: Análisis de contenido. Enseñanza nocturna. Trabajadores-estudiantes.

\section{INTRODUÇÃO}

Na história da investigação científica, a credibilidade concedida ao Positivismo e às metodologias da pesquisa quantitativa nas Ciências Naturais e Exatas implicou, em certa medida, uma tentativa bem-sucedida de transposição desse tipo de pesquisa para o campo das Ciências Humanas e Sociais, embora tais ciências não pesquisem fatos que apresentam encadeamento lógico e com regularidade passível de observação e análise por meio de mensurações estatísticas.

Com efeito, desde a última metade do século passado, na Europa e nos Estados Unidos e, mais precisamente, a partir dos anos de 1980no Brasil, a pesquisa na educação passou por mudanças significativas no que concerne à compreensão do próprio campo científico em termos de delimitação teórica, metodológica e das possibilidades de investigação dos fenômenos educacionais.

Tal como nas Ciências Humanas em geral, o problema educacional vinha sendo investigado tradicionalmentena perspectiva das análises das Ciências Físicas e Naturais, buscando-se isolar variáveis que pudessem expressar a composição do fenômeno. Dito de outro modo, acreditou-se, durante longo tempo, que a mensuração quantitativa de variáveis básicas do fenômeno educacional seria suficiente para o conhecimento de sua totalidade (TOSTA, 2016). 
As ciências da educação definem-se por um conjunto de especificidades e por elementos que dizem respeito à interface de diversos outros campos na tarefa de desvendar e organizar a realidade educacional. Tal campo caracteriza-se, pois, como uma ciência cujo objeto busca, por um lado, a identificação de elementos culturais que precisam ser assimilados pelos indivíduos para que se tornem verdadeiramente humanos e, por outro lado, concomitantemente, a descoberta de formas adequadas para atingir esse objetivo. (SAVIANI, 1996 em TOSTA, 2016).

Constatada, assim, a dificuldade em se estudar a educação com base nas metodologias quantitativas apenas, observa-se a gradativa entrada e a consolidação da metodologia qualitativa de pesquisa, com enfoque na complexidade das relações humanas e dos fenômenos sociais nos seus diversos contextos e manifestações. Assim, a orientação quantitativa, como procedimento predominante na pesquisa educacional até meados dos anos de 1980, começou a gerar certo desconforto relativamente aos métodos e aos resultados obtidos para a solução de problemas prementes e permanentes apresentados pela educação. É nesse período, quando se observa a penetração no meio acadêmico das denominadas pesquisas qualitativas.

Para Godoy (2005), a investigação qualitativa tem como objetivo a obtenção de dados descritivos minuciosos sobre pessoas, lugares e processos interativos por meio do contato direto do pesquisador com a situação estudada. Procura-se, assim, compreender os fenômenos, segundo a perspectiva dos sujeitos, ou seja, dos participantes do estudo. Acrescenta-se, ainda, que esse tipo de investigação rastreia o problema e possibilita o desenvolvimento de ideias capazes de fecundar futuras investigações. O mesmo autor ressalta que os dados coletados pelas pesquisas qualitativas devem ser analisados de forma diferenciada dos dados provenientes de estudos quantitativos, o que se traduz num desafio para os pesquisadores, especialmente no que se refere à compreensão e ao refinamento dos resultados das investigações.

Com base na premissa relativa à produção teórica, o autor apresenta a epistemologia qualitativa. Tal conceito refere-se ao ato de empreender a pesquisa nas Ciências Humanas e Sociais como um processo de comunicação dialógica, característica particular dessas ciências, tendo vista que o homem, permanentemente, comunica-se nos diversos espaços sociais em que vive, contrapondo-se à orientação quantitativa como procedimento dominante na pesquisa educacional.

Como ressalta González Rey (2005), essa dicotomia entre quantitativo e qualitativo pode ser superada diante da possibilidade de trabalhar com ambas as técnicas, com vistas à construção do conhecimento. A realidade concreta é o lugar a ser observado e cotejado por um referencial teórico que pode refutar ou alterar, total ou parcialmente, as hipóteses definidas no início dos estudos.

Dessa forma, os estudos no campo da educação vêm abrangendo várias temáticas sob diferentes perspectivas: filosófica, histórica, antropológica, política, psicológica, demográfica, dentre outras, considerando a interdisciplinaridade. Inspiradas nessas tendências, as investigações têm se constituído, cada vez mais, como sistemas abertos e flexíveis, compostos por correntes diferenciadas, sendo, ao mesmo tempo, problematizadas, rom- 
pendo ou rompidas e transgredindo cânones estabelecidos nas pesquisas no campo educacional. Desde então, autores vêm se apropriando de diferentes procedimentos e técnicas de abordagem dos fenômenos, dentre elas, a Análise de Conteúdo.

Bardin (2011), afirma que essa técnica se desenvolveu, histórica e primeiramente, nas práticas do jornalismo em torno de 1915, nos Estados Unidos, por meio da mensuração do grau de sensacionalismo dos artigos publicados em jornais e revistas. Essa mensuração partia, a princípio, da contagem das palavras, do tamanho delas e de suas localizações no texto. Em outros termos, a análise incidia sobre a diagramação das notícias em veículos impressos, na medida em que a disposição das mesmas não era casual, e sim uma medida de sua importância, prioridade, etc.

Tal vertente de apreciação, no período compreendido entre a Primeira e a Segunda Guerra Mundial, passou a ser utilizada na análise e no estudo de propagandas governamentais visando à interpretação de códigos secretos (e ideológicos) nas peças de cunho político. Por essa razão, uma das primeiras definições do termo Análise de Conteúdo foi cunhada por Berelson e Lazarfeld (1948), conhecida como modelo berelsoniano. Esses autores conceituaram esse procedimento como sendo: "uma técnica de investigação que tem por finalidade a descrição objetiva, sistemática e quantitativa do conteúdo manifesto da comunicação" (BARDIN, 2011, p. 24).

No início da década de 1970, estudiosos franceses, dentre eles a própria Laurence Bardin, passaram a manifestar suas insatisfações com a definição de Berelson e Lazarfeld e com a rigidez de seus métodos, inquirindo sobre a validade do procedimento para análise dos dados e dos resultados das investigações. Dessa averiguação, resultou outro entendimento da Análise de Conteúdo que buscou superar o caráter exclusivamente descritivo; desta feita a função era a obtenção de inferências, baseadas em indicadores de frequência, que poderiam auxiliar na análise detalhada das causas e dos objetivos de determinados fenômenos. Essa percepção da técnica provocou, aos poucos, a adesão de pesquisadores de diferentes áreas, como a linguística, a etnologia, a história, a comunicação, a psiquiatria, a educação, as ciências políticas, dentre outras.

Contudo, constata-se que autores e pesquisadores iniciantes e, mesmo os experientes dessas áreas de conhecimento têm se apropriado da técnica da Análise de Conteúdo de forma pouco rigorosa. Em outros termos, a assimilação dessa técnica tem levado à superficialidade e à banalização de seu uso, na medida em que se deixa de lado as recomendações e as etapas necessárias ligadas aos procedimentos sistematizados e obrigatórios ao seu emprego para além das impressões de senso comum. Ao se usar essa técnica sem o rigor exigido, corre-se o risco de se afastar da denominada vigilância epistemológica do pesquisador, caindo no abismo da sociologia espontânea, meramente descritiva, que carece de maior explicação e compreensão da realidade, ou seja, a simples referência à prova experimental não passa de uma tautologia, enquanto não for acompanhada por uma explicação de seus pressupostos teóricos que servem de base a uma verdadeira experimentação, como tão bem explicita Bourdieu, Chamboredon e Passeron (2007).

Em termos gerais, os modos como a Análise de Conteúdo são utilizados, contrapõem-se à recomendação de Bardin, sobretudo em relação à ênfase que deveria ser dada aos denominados procedimentos sistematizados, conforme explica a própria autora: 
Um conjunto de técnicas de análise das comunicações visando obter por 'procedimentos sistemáticos' e objetivos de descrição do conteúdo das mensagens indicadores (quantitativos ou não) que permitam a inferência de conhecimentos relativos às condições de produção/recepção (variáveis inferidas) dessas mensagens. (BARDIN, 2011, p. 48, grifos nossos).

Ressaltando a importância do rigor na utilização dessa técnica, a pesquisadora francesa afirma que todas as suas etapas devem ser seguidas para explicitar e sistematizar o conteúdo das mensagens, diminuindo-se, assim, tanto as incertezas, quanto as deduções lógicas obtidas e justificadas, referentes às mensagens tomadas como corpus ou documentos submetidos à análise.

O avanço das tecnologias digitais tem fomentado, a partir do século XIX, a aplicação da Análise de Conteúdo na Educação tanto na sua base de "hardwares", quanto na de "softwares", as quais têm se apresentado como um número de dados impossíveis de serem manipulados manualmente (OLIVEIRA et all, 2003, BARDIN, 2011; VOSGERAU, POCRIFKA, SIMONIAN, 2016).

Tendo em vista a importância da Análise de Conteúdo na pesquisa qualitativa, este artigo tem como objetivo descrever e analisar como essa técnica foi utilizada em um estudo realizado entre os anos de 2014 a 2017, que abordou o ensino noturno e um grupo detrabaIhadores-alunos na difícil tarefa em conciliar trabalho e estudo. Para isso, desenvolveu-se um estudo em duas instituições da Rede Federal de Educação Profissional, Científica e Tecnológica, de Minas Gerais (RFEPCT ${ }^{1}$ ) e realizou-se entrevistas semi estruturadas, cujos resultados foram interpretados à luzdas premissas teóricasda técnica de Análise de Conteúdo.

Nesta introdução, contextualiza-se a temática como um desafio aos pesquisadores no campo das diversas ciências. O segundo tópico desenvolve as questões gerais relativas à pesquisa realizada com os trabalhadores-alunos, sendo dividido em quatro partes: na primeira delineiam-se os objetivos da pesquisa, descrevendo o cenário na qual estava inserida; na segunda são descritas as categorias iniciais; na terceira são abordadas as categorias intermediárias; e na quarta e última parte são apresentadas as categorias finais, identificadas como a síntese da aplicação da referida técnica. No tópico de análise dos resultados, são tecidos os enredos conclusivos relativos às categorias finais surgidas na Análise de Conteúdo. Por fim, são apresentadas as considerações finais que apreciam, em especial, os cuidados que devem ser tomados na utilização da Análise de Conteúdo na pesquisa em educação.

\section{Desenvolvendo a Análise de Conteúdo em uma pesquisa em educação}

Ao longo da história, o ensino noturno brasileiro, não vem ofertando a professores e alunos adequadas condições de ensino e aprendizagem, levando-se em consideração que o personagem central é quase sempre o trabalhador-aluno que necessita de apoio e acompanhamento especiais.

1 A partir de 2008, houve um reordenamento da Rede Federal de Educação Profissional Científica e Tecnológica, devido à Lei no 11.892 de 2008, que instituiu RFEPCT, com a criação dos IFTECs. (CAIRES; OLIVEIRA, 2016). 
Em geral, o ensino noturno e, em particular, o profissionalizante, ao longo da história, tem sido oferecido de forma suplementar, ou seja, atende-se prioritariamente ao público do turno diurno e, para aqueles que estudam no ensino noturno, resta-lhes, na maioria dos casos, um arremedo de escola, de qualidade questionável. (PIRES, 2007, p. 25).

Os fracos desempenhos escolares que levam à evasão escolar dos referidos alunos vêm evidenciando uma trajetória escolar marcada por descontinuidades, fracassos e por políticas públicas e institucionais que não contemplam as peculiaridades e necessidades desses sujeitos (HADDAD, 1991 e TENCA 1982). Se a escola, geralmente, já é excludente nos diferentes níveis de educação básica, como analisar essa situação no âmbito da educação profissional, ofertada para o trabalhador-aluno que estuda no turno da noite após uma longa jornada de trabalho? Existiria uma relação construída entre o cotidiano, a vida desse trabalhador-aluno e a escola na qual está inserido?

A partir dessa perspectiva, a pesquisa contemplou a investigação de campo, partindo, primeiramente, da análise quantitativa, por meio da análise dos dados levantados pelos questionários estruturados. Em seguida, foi feita uma análise qualitativa dos dados coletados à luz das entrevistas individuais semi estruturadas e da descrição dos conteúdos das mensagens e dos indicadores. Isso permitiu a inferência de conhecimentos, procedendo-se à Análise do Conteúdo, sob a ótica de Bardin (2011).

AAnálise de Conteúdo se realiza adequadamente na prática da investigação, conforme preconizada por Bardin. Por isso, este estudo refere-se aos processos e resultados de pesquisa realizados com 09 estudantes trabalhadores matriculados nos Cursos Técnicos de Edificações de duas instituições vinculadas à RFEPCT: uma localizada na cidade de Ouro Preto e outra na cidade de Belo Horizonte, ambas situadas no estado de Minas Gerais. Esse grupo de estudantes representou uma amostra dos 86 sujeitos que responderam a um questionário estruturado seguido da análise de seus dados, que se processou na fase quantitativa da pesquisa que antecedeu à análise qualitativa descrita neste trabalho.

Para tanto, foram realizadas entrevistas individuais, gravadas com a autorização dos alunos, obtendo satisfatória audibilidade dos conteúdos dos discursos. A duração das entrevistas durou cerca de 20 minutos, e foram realizadas nas próprias instituições pesquisadas, nos horários antecedentes ou posteriores aos das aulas, ou nos intervalos entre elas, totalizando, aproximadamente, três horas de gravação. As transcrições das entrevistas geraram 72 páginas, nas quais foram preservadas, na íntegra e sem revisões de qualquer ordem, a linguagem dos entrevistados. Os dados coletados foram organizados, divididos e analisados, segundo as categorias de análise identificadas, que se apresentaram de modo interligado. Esse procedimento foi indispensável para o estudo das percepções das experiências dos trabalhadores-alunos ouvidos na pesquisa.

A investigação relacionou-se fundamentalmente à dualidade estrutural, considerando-se as mediações e contradições, na medida em que contemplou a educação profissional e ao mesmo tempo centralizou a atenção nos trabalhadores-alunos. Estes, ao longo de 
seus percursos estudantis, têm de conciliar trabalho e estudo, quase sempre em condições precarizadas, tanto no espaço do trabalho quanto no escolar.

Ao longo da história, a educação brasileira vem sendo marcada por uma nítida distribuição de indivíduos por classes sociais determinadas. Assim, existe, essencialmente, uma escola que reproduz uma sociedade desigual, uma escola que é regida por leis que foram criadas para favorecer a classe social dominante, objetivando reproduzir e perpetuar a desigualdade social, favorecendo, portanto, os já favorecidos.

Procurou-se, dessa maneira, empregar a Análise de Conteúdo a fim de responder questionamentos da problemática da pesquisa, conforme referido. Assim sendo, os dados coletados pelas entrevistas requereram o emprego de técnicas tais como: a organização da análise; a codificação dos resultados; as categorizações; e, por fim, as inferências e a análise das comunicações. Portanto, essas diferentes fases da Análise de Conteúdo, de acordo com a Figura 1 apresentada a seguir, exprimem-se em torno de três etapas ou fases sequenciais: "1. A pré-análise; 2. A exploração do material; 3. O tratamento dos resultados: a inferência e a interpretação." (BARDIN, 2011, p. 125).

Figura 1 - Desenvolvimento da Análise de Conteúdo.

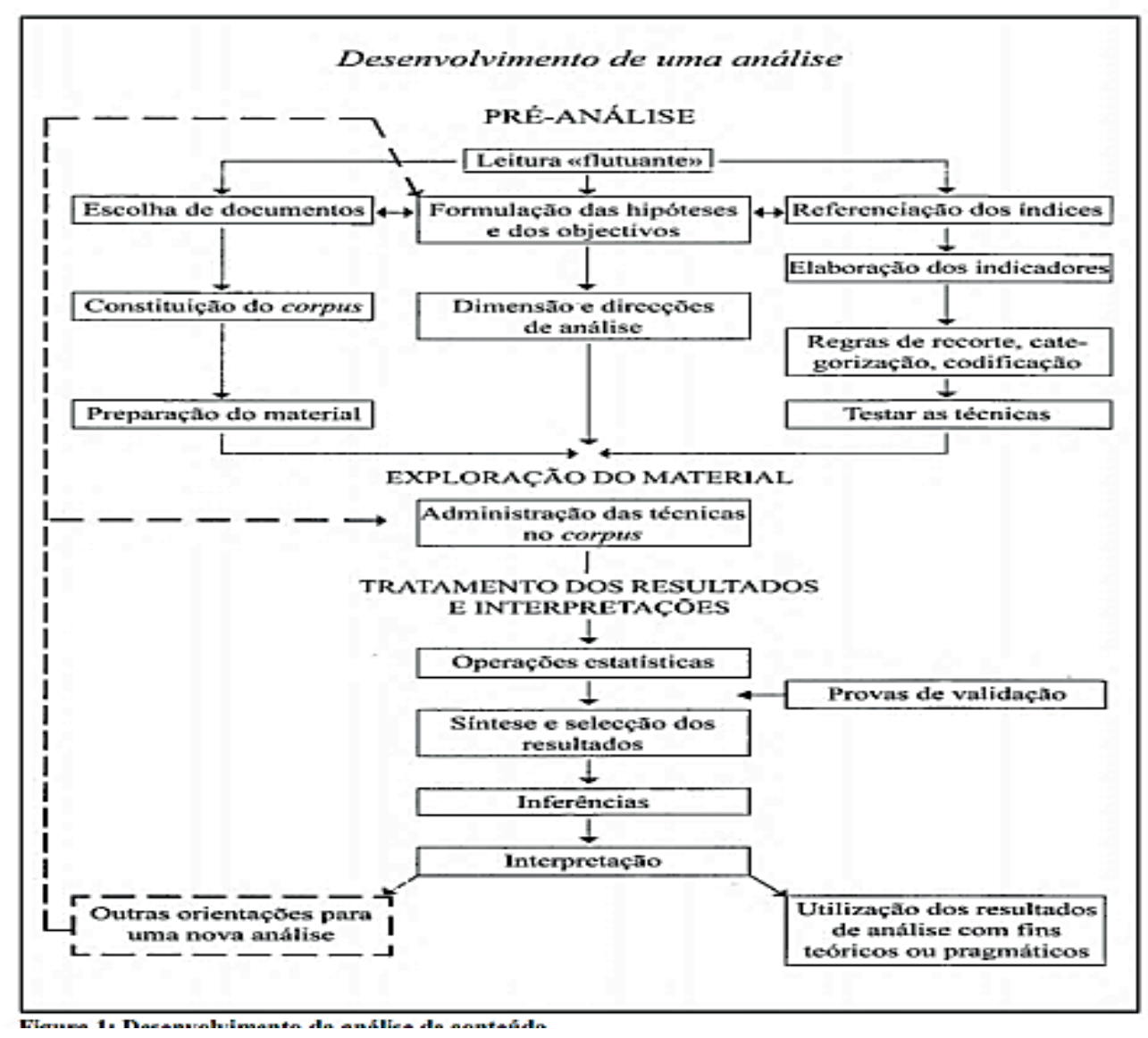

Fonte: Bardin (2011, p. 132).

De acordo com Bardin (2011, p. 125), para aplicação adequada e precisa da Análise do Conteúdo, deve-se privilegiar como ponto de partida a organização dos dados "para tor- 
nar operacionais e sistematizar as ideias iniciais." Nessa fase, formulam-se as hipóteses e elaboram-se os indicadores que fundamentarão, ao final, a interpretação dos dados.

A fase de organização dos dados é denominada pela autora como primeira fase, ou seja, a pré-análise, onde são sistematizadas as ideias tendo em vista os objetivos gerais e específicos da pesquisa. A organização dos dados foi feita mediante a leitura dos textos das transcrições das entrevistas realizadas com os sujeitos da pesquisa, como já acentuado anteriormente, que se constituiu como corpus que seria submetido aos procedimentos de análise.

Em seguida, procedeu-se à leitura flutuante do material de análise e à formulação das hipóteses e dos objetivos, que, segundo Bardin (2011), constituíram-se como o primeiro contato com o material analisado atendendo à regra da não seletividade, ou seja, o documento foi apreciado em sua íntegra, sem recortes ou censuras.

Ressalta-se que o corpus analisado atendeu à regra da homogeneidade. De acordo com Bardin (2011, p.128), a regra da homogeneidade deve ser estabelecida, obedecendo a critérios precisos de escolha. Especificamente na investigação em pauta, reitera-se que o objeto foi previamente definido, ou seja, o Ensino Noturno Profissionalizante e os sujeitos, os trabalhadores-alunos. Adverte-se que, ao se efetuar a seleção dos sujeitos desta pesquisa, que representavam o universo estudado, foi verificado que estes guardavam entre si certa semelhança e homogeneidade: alunos trabalhadores, com contrato formal de trabaIho, e matriculados no mesmo curso técnico de uma mesma rede, a RFEPCT.

Na segunda fase, mais extensa, procedeu-se à exploração e tratamentodo material, que é denominada de operação de codificação, devendo-se considerar os recortes dos textos oriundos das entrevistas, a contagem, a classificação e integração das informações em categorias simbólicas ou temáticas.

Bardin (2011, p.133), define a operação de codificação como a transformação realizada segundo regras precisas dos dados brutos do texto, sendo que essa transformação é efetuada por recorte, agregação e enumeração, permitindo atingir a representação do conteúdo ou da sua expressão.

A mesma autora (2011, p.135), também define tema como uma unidade de significação que se liberta naturalmente do texto analisado, segundo critérios relativos à teoria que serve de guia à leitura, sendo geralmente utilizado como unidade de registro para se estudar motivações e opiniões.

Dessa forma, considerando ambas as definições precedentes, nessa segunda fase de codificação, foi feito o recorte do material em unidades de registro ou de significação. Tais unidades de registro se constituíram no recorte de palavras, temas eixos ou "núcleos de sentido" que compuseram as falas dos sujeitos, os personagens como familiares e amigos e os fatos e acontecimentos em suas histórias de vida. Esses processos de recortes permitirão a formação das categorias, que, de uma forma geral, possui grande importância em toda e qualquer atividade científica (BARDIN, 2011, p. 148).

Assim, após o recorte do material, utilizou-se o procedimento por caixas que se constituem como o método das categorias, espécie de gavetas ou rubricas que permitem 
a classificação dos elementos de significação constitutivos da mensagem. Adverte-se que "a categorização, passagem dos dados brutos para os dados organizados, não introduz desvios no material, mas dá a conhecer índices invisíveis, ao nível dos dados brutos." (BARDIN, 2011, p. 149).

O emprego dessa categorização se justifica por se constituir como a técnica mais antiga e utilizada na Análise de Conteúdo e, ainda, por considerar as falas dos sujeitos pesquisados, submetendo-as ao "crivo da classificação e do recenseamento, segundo a frequência de presença (ou de ausência) de itens de sentido." (BARDIN, 2001, p. 43).

Nestes termos, o texto originado das entrevistas foi recortado em unidades de registro, sendo identificadas as palavras-chave que se constituíram como a segunda categorização. As palavras-chave de cada depoimento foram agrupadas de acordo com a relação de semelhança entre os temas, constituindo-seem categorias intermediárias que, ao serem estratificadas e organizadas, possibilitaram definir as categorias finais da pesquisa e a elaboração das inferências. Essa elaboração pode ser definida "como uma operação lógica, pela qual se admite uma proposição em virtude de sua ligação com outras proposições já aceitas como verdadeiras." (BARDIN, 2011, p. 45).

Identificadas a codificação e a categorização, foram destacados os indicadores que conduziram às deduções lógicas ou inferências, isto é, às palavras-chaves, o que possibilitou conhecer as diferenças e semelhanças entre os trabalhadores-alunos do turno noturno, nos loci de pesquisa, organizando-as em categorias por meio do processo indutivo e inferencial, conforme explicitado a seguir. ${ }^{2}$

Portanto, a classificação dos elementos em categorias permitiu o agrupamento das partes comuns existentes nas falas dos sujeitos se configurando como um processo caracterizado como estruturalista ${ }^{3}$, no sentido da construção de um modelo explicativo da realidade como uma estrutura que se fracionaem partes que se inter-relacionam. A seguir, detalha-se o processo de obtenção das três categorias simbólicas ou temáticas que se consolidaram na segunda fase da aplicação da Análise de Conteúdo, qual seja, a fase da exploração e do tratamento das entrevistas submetidas à análise.

\section{$1^{\circ}$ - Categorias Iniciais}

As categorias iniciais intencionaram identificar as primeiras impressões acerca dos conteúdosdas entrevistas, tendo-se optado neste estudo pelo roteiro de entrevistas. Essas

2 Ressalta-se que não houve a utilização de softwares de computadores auxiliares para a organização do material e codificação dos dados.

3 Sobre o estruturalismo conferir as obras paradigmáticas de Lèvi- Srrauss, Antropologia Estrutural I e II:LEVI-STRAUSS. C. Anthropologiastructurale. Paris, Plon/Agora, 1958; LEVI-STRAUSS. C. Anthropologiestructuraledeux. Paris, Plon/Pocket, 1973.Livros em que o antropólogo elabora o método estrutural que parte do pressuposto de que cada sistema é um jogo de oposições, presenças e ausências, constituindo uma estrutura, onde o todo e as partes são interdependentes, de tal forma que as modificações que ocorrem num dos elementos constituintes implica a modificação de cada um dos outros e do próprio conjunto. 
categorias foram criadas e nomeadas, em conformidade com os dados que as constituíram, quais sejam: os objetivos gerais e específicos; a problemática revelada pelas questões da pesquisa; a pesquisa bibliográfica e a pesquisa quantitativa e exploratória.

As categorias iniciais elencadas foram as escolhidas como eixos norteadores do roteiro das entrevistas realizadas com os alunos logo após a entrada no campo de pesquisa e análise quantitativa, são elas: aspectos de vida dos trabalhadores-alunos; relação com o trabalho; relação com a escola e relação entre trabalho e escola.

Assim, a primeira categoria diz respeito aos aspectos da história de vida dos trabaIhadores-alunos, objetivando identificar se as histórias dos sujeitos entrevistados possuíam similaridades em relação ao local de nascimento, à constituição familiar, dentre outras. A segunda categoria, a relação com o trabalho, identificou a trajetória laboral dos trabalhadores-alunos, contemplando, inclusive, suas atuais ocupações. Aterceira categoria, a relação com a escola, definiu a trajetória escolar dos trabalhadores-alunos, desde seus primeiros anos na escola até suas pretensões futuras. Por fim, a última categoria, a relação entre trabalho e escola, referiu-se ao processo de conciliação entre trabalho e estudo.

\section{$2^{\circ}$ - Categorias Intermediárias}

A partir do conjunto das quatro categorias inicias, foram selecionadas 18 categorias intermediárias que emergiram dos dados. Essas categorias contemplaram as narrativas dos entrevistados, o referencial teórico e as observações. À medida que elas se entrelaçavam, formavam cadeias de significações que conduziram às categorias intermediárias.

A primeira das quatro categorias iniciais deu origem às três categorias intermediárias; a segunda categoria formou outras três categorias intermediárias; a terceira categoria gerou oito categorias intermediárias; e a última categoria redundou em quatro categorias. A Tabela 1 apresenta a lista de referência ou de codificação (de 1 a 18) que foi elaborada, relacionando as categorias iniciais com as categorias intermediárias.

Tabela 1 - Relação entre as Categorias Iniciais e as Categorias Intermediárias

\begin{tabular}{|ll|c|}
\hline \multicolumn{2}{|c|}{ Aspectos dahistória de vida dos sujeitos } & Frequência \\
\hline 1) & Família: origem / naturalidade / tamanho / incentivo para estudos & 45 \\
\hline 2) & Genitores: ocupação / escolaridade / região de origem & 25 \\
\hline 3) & Relação com a família: tempo dedicado / distância ou aproximação & 12 \\
\hline \multicolumn{1}{|c|}{ Relação dos sujeitos com o trabalho } & 82 \\
\hline \multicolumn{2}{|c|}{ TOTAL } & 64 \\
\hline $\begin{array}{l}\text { 4) } \\
\text { Trajetória laboral atual: início da atividade / idade / natureza da atividade / local / } \\
\text { incentivo dos pais }\end{array}$ & 73 \\
\hline 5) & Atividade laboral atual: carga horária / local / área & 19 \\
\hline 6) & Tratamento diferenciado, relativo ao trabalho e ao estudar & 159 \\
\hline
\end{tabular}




\begin{tabular}{|c|c|c|}
\hline \multicolumn{2}{|r|}{ Relação dos sujeitos com a escola } & \\
\hline 7) & Trajetória escolar: início da atividade/ idade/ desempenho geral/ turno/ interrupção & 69 \\
\hline 8) & Motivação para cursar a Educação Profissional & 13 \\
\hline 9) & Tempo dedicado aos estudos fora da escola: local / tempo & 12 \\
\hline 10) & Tratamento diferenciado dos professores para com os trabalhadores-alunos & 8 \\
\hline 11) & Tratamento diferenciado dos trabalhadores-alunos & 29 \\
\hline 12) & Desempenho escolar: relação da aula prática e com a aula teórica & 34 \\
\hline 13) & Relações na escola: colegas da turma e colaboração mútua entre eles & 13 \\
\hline 14) & Pretensões futuras & 28 \\
\hline & TOTAL & 206 \\
\hline \multicolumn{2}{|r|}{ Relação entre o trabalho e à escola } & \\
\hline 15) & Relação do curso técnico com o trabalho & 18 \\
\hline 16) & Conciliação entre trabalho e estudo & 72 \\
\hline 17) & Transposição de conhecimentos para o trabalho; estudo e vida & 40 \\
\hline 18) & Trajeto: horários de saída e chegada / duração da trajetória e transporte & 41 \\
\hline & TOTAL & 171 \\
\hline
\end{tabular}

Fonte: Dados da Pesquisa.

A coluna de frequência apresentada na Tabela 1 representa a inserção de uma unidade de registro ou de significação referente às categorias intermediárias no âmbito das falas dos trabalhadores-alunos entrevistados. Como definido anteriormente, essas unidades de registro se baseiam no pressuposto de que o significado do que está implícito na aparição de um item de sentido ou de expressão torna-se mais significativa quanto mais a frequência se repetir. Portanto, "a regularidade quantitativa de aparição se constitui como aquilo que se considera como significativo" (BARDIN, 2011, p. 139).

Gráfico 1 - Gráfico de Pareto para os Itens de Sentido por Categoria Primária

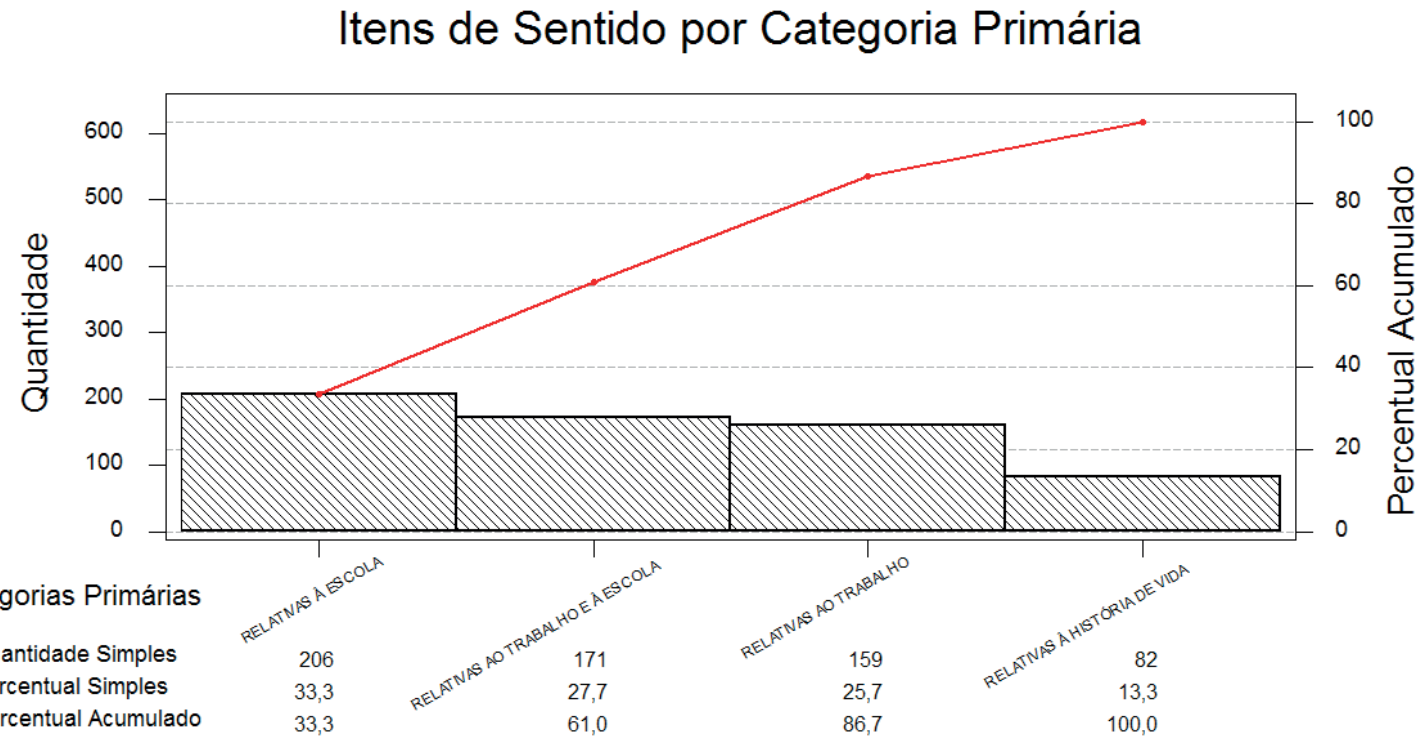

Fonte: Dados de Pesquisa. 
Conforme o Gráfico de Pareto 4 , que apresenta os itens de sentido vinculados às categorias primárias, observa-se que foram mais frequentes as relativas à Escola, que totalizou (206) aparições. Em segundo lugar, situam-se os dados referentes à relação Trabalho e Estudo (171); em terceiro lugar, o dado atinente, apenas, ao Trabalho (159); e em quarto e último lugar, a História de Vida dos trabalhadores-alunos, que totalizou (82) unidades de sentido.

Constatou-se, assim, que os trabalhadores-alunos se sentiram mais à vontade para responderem às questões relativas tanto às suas experiências na vida escolar, quanto às relacionadas à conciliação entre estudo e trabalho. Esse dado evidenciou a pertinência e a importância da análise dessa última variável, intimamente ligada, à problemática e ao objetivo da investigação relativa aos trabalhadores-alunos.

Portanto, alguns excertos das falas dos sujeitos foram considerados como indicadores das referidas categorias intermediárias que fizeram interlocução com os aportes teóricos que, por sua vez, referendaram a pesquisa realizada nos dois loci de investigação. Ressalta-se, também, que essas categorias intermediárias foram obtidas pelos excertos das falas dos sujeitos entrevistados e, em seguida, confrontadas com o referencial teórico pesquisado, obtendo-se os possíveis resultados da pesquisa.

\section{$3^{\circ}$ - Categorias Finais}

A terceira fase da Análise de Conteúdo se refere ao tratamento dos resultados, relativos à inferência e à interpretação, buscando-se captar, nos depoimentos dos trabalhadores-alunos, os conteúdos manifestos e/ou ocultos presentes nas suas falas. Os itens/ questões considerados semelhantes e/ou diferentes que foram justapostos propiciaram o estudo vis a vis das diferentes variáveis, possibilitando a realização do que Bardin (2011) denomina de Análise Comparativa.

As categorias finais foram construídas com o intuito de respaldar as interpretações e possibilitar a inferência dos resultados. Portanto, elas representaram a síntese do conjunto das significações identificadas no decorrer da análise dos dados do estudo.

Desse modo, chegou-se à exclusão mútua, atinente à homogeneidade, à pertinência, à objetividade, à fidelidade e à produtividade, características consideradas por Bardin (2011) de boa qualidade. Afinal,

[...] a análise de conteúdo constitui um bom instrumento de indução para se investigarem as causas (variáveis inferidas) a partir dos efeitos (variáveis de inferência ou indicadores; referência no texto), embora o inverso, predizer os efeitos a partir

4 Diagrama ou Gráfico de Pareto se constitui como um gráfico de barrasque ordena as frequências das ocorrências, partindo da maior para a menor, permitindo a priorização dos problemas ou temas. Mostra, ainda, a curva de porcentagens acumuladas. Sua maior utilidade é a de permitir fácil visualização e identificação das causas ou problemas mais importantes, possibilitando a concentração de esforços sobre os mesmos. Para a confecção do gráfico, lançou-se mão do software estatístico MINITAB®. 
de fatores conhecidos, ainda não esteja ao alcance das nossas capacidades. (BARDIN, 2011, p. 169).

Dessa maneira, as categoriais iniciais e as intermediárias apresentadas anteriormente possibilitaram a construção das categorias finais, as quais viabilizaram as interpretações e permitiram inferir os resultados. As categorias finais representam a síntese do somatório das significações identificadas no desenvolvimento da Análise de Conteúdo que foi realizada. A constituição final foi formada por 21 categorias, conforme consta no Quadro 1 a seguir, que evidencia uma redução dos dados brutos coletados, oriundos das entrevistas realizadas com os trabalhadores-alunos.

Quadro 1 - Formação das Categorias Finais (1-4)

\begin{tabular}{|c|c|}
\hline \multicolumn{2}{|c|}{ CATEGORIAS PRIMÁRIAS } \\
\hline $\begin{array}{c}\text { Relativas aos aspectos da história de vida dos } \\
\text { trabalhadores-alunos }\end{array}$ & Relativas ao trabalho \\
\hline \multicolumn{2}{|c|}{ CATEGORIAS INTERMEDIÁRIAS } \\
\hline $\begin{array}{l}\text { Família: origem / naturalidade / tamanho / incentivo } \\
\text { dos pais }\end{array}$ & $\begin{array}{l}\text { Trajetória Laboral: Início da atividade / idade / natu- } \\
\text { reza da atividade / local e incentivo dos pais }\end{array}$ \\
\hline \multicolumn{2}{|c|}{ INDICADORES DE CÓDIGOS NORTEADORES } \\
\hline $\begin{array}{l}\text { - Evidência da existência de peculiaridades que } \\
\text { marcaram as trajetórias dos trabalhadores-alu- } \\
\text { nos; } \\
\text { - Constatação de suas migrações para uma cidade } \\
\text { maior em busca de maiores e melhores condições } \\
\text { de vida; } \\
\text { - Percepção de carência de capital cultural, social e } \\
\text { financeira; } \\
\text { - A trajetória de vida desses sujeitos que, aparente- } \\
\text { mente, se apresenta como um obstáculo aos seus } \\
\text { desempenhos escolares }\end{array}$ & $\begin{array}{l}\text { - Constatação da precariedade e da intensificação } \\
\text { das atividades, traduzidas na prematuridade da } \\
\text { inserção laboral e consequente exploração às } \\
\text { quais estiveram submetidos os sujeitos. }\end{array}$ \\
\hline \multicolumn{2}{|c|}{ CATEGORIAS FINAIS } \\
\hline $\begin{array}{l}\text { 1- Dificuldades e peculiaridades, sobretudo, por } \\
\text { migrarem para cidades maiores, conduzindo-os } \\
\text { a uma trajetória de obstáculos no trabalho na } \\
\text { escola e na vida. } \\
\text { - Essas peculiaridades inerentes aostrabalhado- } \\
\text { res-alunos acarretaram tanto dificuldades quanto } \\
\text { saberes tácitos; } \\
\text { - Questão da especificidade e multiplicidade cultural; } \\
\text { - Lutas pela sobrevivência. }\end{array}$ & $\begin{array}{l}4 \text { - Trajetória laboral marcada pela precariedade, } \\
\text { inserção prematura, intensificação e exploração } \\
\text { dos trabalhadores. } \\
\text { • Exploração da mais valia; } \\
\text { - Precariedade do trabalho. }\end{array}$ \\
\hline
\end{tabular}

Quadro 1 - Formação das Categorias Finais (5-12)

\begin{tabular}{|c|c|}
\hline \multicolumn{2}{|c|}{ CATEGORIAS PRIMÁRIAS } \\
\hline Relativas ao trabalho & Relativas à escola \\
\hline \multicolumn{2}{|c|}{ CATEGORIAS INTERMEDIÁRIAS } \\
\hline Atividade laboral atual: carga horária / local e área & $\begin{array}{c}\text { Trajetória escolar: Início da atividade / idade / local / } \\
\text { desempenho geral / turno / interrupções }\end{array}$ \\
\hline
\end{tabular}




\section{INDICADORES DE CÓDIGOS NORTEADORES}

\begin{tabular}{|c|c|}
\hline $\begin{array}{l}\text { - Sentimentos de satisfação e insatisfação com o } \\
\text { trabalho atual, devido aos baixos níveis salariais. }\end{array}$ & $\begin{array}{l}\text { - Evidência de uma trajetória marcada pela dificul- } \\
\text { dade dos trabalhadores-alunos de se manterem e } \\
\text { permanecerem na escola; } \\
\text { - O Ensino Profissionalizante como possibilidade de } \\
\text { retorno à vida escolar; } \\
\text { - Os cursos noturnos avaliadoscomo catalisadores } \\
\text { de uma contradição social básica, inserindo traba- } \\
\text { lhadores que não tiveram acesso à escola e para } \\
\text { competirem no mercado de trabalho. }\end{array}$ \\
\hline \multicolumn{2}{|c|}{ CATEGORIAS FINAIS } \\
\hline $\begin{array}{l}\text { 5-Insatisfação e busca da melhoria de vida. } \\
\text { • Motivação para mudançasnas trajetórias labo- } \\
\text { rais e de vida. }\end{array}$ & $\begin{array}{l}\text { 7- Trajetória dos trabalhadores-alunos marcada } \\
\text { pela dificuldade de permanência na escola. } \\
\text { 8- O ensino profissional como possibilidade de } \\
\text { retorno à escola. } \\
\text { - Exclusão da escola comum; } \\
\text { - Dificuldades em dominar a dinâmica e o cotidiano } \\
\text { ante a sua linguagem e os símbolos das escolas. }\end{array}$ \\
\hline
\end{tabular}

Quadro 1 - Formação das Categorias Finais (13-19)

\begin{tabular}{|c|}
\hline CATEGORIAS PRIMÁRIAS \\
\hline Relativas à escola \\
\hline CATEGORIAS INTERMEDIÁRIAS \\
\hline Tratamento Diferenciado dos Trabalhadores-alunos \\
\hline INDICADORES DE CÓDIGOS NORTEADORES \\
\hline $\begin{array}{l}\text { - Trabalhadores-alunos não tinham atendimento de acordo com as suas necessidades; } \\
\text { - Frustração com a situação de abandono do PROEJA; } \\
\text { - Percepção do tratamento diferenciado por parte da instituição, sobretudo, quanto à disponibilidade dos } \\
\text { professores para as turmas do PROEJA; } \\
\text { - Clareza de que o PROEJA era preterido em relação aos demais cursos, ofertados pelainstituição pes- } \\
\text { quisada, sobretudo,nos Cursos de Graduação; } \\
\text { - Reconhecimento da excelente qualidade da escola e da importância da continuidade do PROEJA. }\end{array}$ \\
\hline CATEGORIAS FINAIS \\
\hline $\begin{array}{l}\text { 13- Reconhecimento da qualidade da instituição, mas os trabalhadores-alunos se sentiam excluí- } \\
\text { dos e preteridos em relação aos outros turnos de ensino e aos seus alunos. } \\
\text { - Falta de sintonia entre os gestores/professores e os alunos; } \\
\text { 14- Classificação, categorização e diferenciação da cultura vigente na escola e as realidades labo- } \\
\text { ral e social dos trabalhadores-alunos. }\end{array}$ \\
\hline
\end{tabular}

Quadro 1 - Formação das Categorias Finais (20-23)

\begin{tabular}{|c|c|}
\hline \multicolumn{2}{|c|}{ CATEGORIAS PRIMÁRIAS } \\
\hline Relativas à escola & Relativas ao trabalho e à escola \\
\hline \multicolumn{2}{|c|}{ CATEGORIAS INTERMEDIÁRIAS } \\
\hline \multicolumn{2}{|c|}{ Iransposição de conhecimentos: para o trabalho, } \\
estudo e a vida
\end{tabular}




\begin{tabular}{|c|c|}
\hline $\begin{array}{l}\text { - Os trabalhadores-alunos não trabalhavam na área } \\
\text { ligada ao curso técnico que frequentavam; } \\
\text { - Busca de novas oportunidades no mercado de } \\
\text { trabalho; } \\
\text { - A escolha do curso se ligaria mais à uma busca de } \\
\text { mudança radical em suas profissões. }\end{array}$ & $\begin{array}{l}\text { - Ausência de diálogo entre a realidade do trabalho } \\
\text { e a realidade da escola. }\end{array}$ \\
\hline \multicolumn{2}{|c|}{ CATEGORIAS FINAIS } \\
\hline $\begin{array}{l}\text { 20- Busca de novas oportunidades, sem mudar } \\
\text { radicalmente a condição atual. } \\
\text { - Relação entre trabalho e educação que era difícil } \\
\text { conciliar. }\end{array}$ & $\begin{array}{l}\text { 22- Percepção das diferenças entre os espaços } \\
\text { laborais e espaços escolares } \\
\text { - Atividades escolares e laborais baseadas em sím- } \\
\text { bolos e regras específicas; } \\
\text { - Educação como uma instância específica e dife- } \\
\text { renciada da atividade laboral. }\end{array}$ \\
\hline
\end{tabular}

Fonte: Dados da Pesquisa.

Observa-se, a partir da formulação e estudo das três categorias, que o emprego da Análise de Conteúdo constitui-se como um bom instrumento de indução para se investigar as causas a partir dos efeitos referenciados nas falas dos sujeitos.

Para analisar as categorias finais obtidas por meio dos depoimentos dos trabalhadores-alunos, optou-se por realizar uma breve análise inferencial de cada uma delas para, assim, captar o cerne dos dados alcançados da pesquisa, atingindo a essência da pesquisa ora desenvolvida ou indicar as potencialidades para pesquisas futuras sobre a temática em questão.

\section{Análise inferencial dos resultados}

O tratamento dos resultados se constituiu na terceira fase das três etapas sequenciais onde se realiza as inferências e a interpretação da análise das comunicações.

Constatou-se que os trabalhadores-alunos de ambas as instituições possuíam peculiaridades, principalmente por migrarem para cidades maiores, o que os levou a vivenciarem uma trajetória difícil e repleta de obstáculos que, de certa forma, interferiu nos seus desempenhos escolares.

Assim, pode-se afirmar como a herança aliada à especificidade cultural, advindas da família, pode interferir nas trajetórias escolares dos trabalhadores-alunos e, consequentemente, na tomada de decisões nas suas escolhas. Essas particularidades, de maneira especial a luta pela sobrevivência, contribuem para que os trabalhadores-alunos desenvolvam diferentes habilidades para superar as dificuldades que Ihes são apresentadas.

Nas falas dos entrevistados, estiveram sempre presentes as realidades educacionais, culturais e econômicas das suas famílias, que influenciaram diretamente em suas trajetórias escolares. Destaca-se que o baixo nível de escolarização dos genitores dos trabalhadores-alunos pode influenciar negativamente nos seus desempenhos escolares, uma vez que a distância da cultura escolar por parte dos pais pode tornar mais difícil a apropriação dessa cultura pelos seus filhos. Contudo, essas famílias incentivavam os estudos dos 
seus filhos, por considerar que a educação se constitui em uma estratégia de investimento e esperança de ascensão social para esses sujeitos.

Os depoimentos que se converteram em categorias evidenciaram a existência de incompatibilidade entre o tempo escolar e o cotidiano de trabalho dos alunos, ou seja, esses sujeitos possuíam uma realidade específica de trabalho e estudo, o que torna necessário promover a articulação entre os tempos de trabalho, de estudo e de sobrevivência. O trabalho é uma importante referência para suas vidas ou uma categoria-chave que pode facilitar o desenvolvimento de suas capacidades técnicas. Em contrapartida, o ensino técnico pode proporcionar-lhes melhoria dos padrões sociais, a partir da concretização de uma aprendizagem mais significativa, garantindo seus direitos de acesso à educação e ao conhecimento.

A análise permitiu observar que os trabalhadores-alunos possuíam uma trajetória laboral marcada pela precarização, pela inserção prematura no trabalho, pela sua intensificação e exploração do trabalho, situação esta, que pode influenciar negativamente seu desenvolvimento cognitivo e, consequentemente, afetar seus desempenhos escolares.

A inserção precoce no mundo laboral foi feita, geralmente, em ocupações não qualificadas que não exigem experiência profissional, traduzindo-se, na verdade, em subempregos, cargas horárias abusivas e situações de riscos físicos, mentais e emocionais.

Embora esses trabalhadores-alunos vivenciem situações de precariedade laboral, eles experienciavam uma situação e uma condição contraditória, expressa na satisfação com o emprego atual, mas na busca por melhores condições de vida, desejando mudar suas trajetórias a partir de melhor nível de escolaridade. De acordo com Togni (2007, p. 32), "os alunos, portanto, buscam nas escolas noturnas muito além de instrução. Buscam igualdade de chances e formas de não exclusão".

Entre os trabalhadores-alunos pesquisados, observou-se que para os que trabalhavam em pequenas empresas ou em casa de família, ocorria incentivo para a continuidade dos estudos. Por outro lado, as grandes empresas não facilitavam e não valorizavam o estudo, embora elas demandem de seus funcionários uma constante qualificação profissional.

Para os trabalhadores-alunos, a trajetória e permanência escolar foram marcadas por dificuldades que, muitas vezes, os levavam a abandonar os estudos, provocando descontinuidades na vida escolar, sobretudo devido à necessidade de trabalhar e não conseguirem conciliar estudo e atividade laboral. Assim, reitera-se que esses trabalhadores-alunos acabam por desistir da escola, permanecendo com baixo nível de escolaridade que, somado à escassez de empregos melhores, acaba por mantê-los em subempregos, impedindo-os de melhorarem suas condições escolares, laborais e sociais.

Nesse sentido, o ensino profissional se apresentou como possibilidade de retorno à escola dos que, inseridos no mundo do trabalho, não tiveram oportunidades de prosseguirem em suas vidas escolares. Devido às suas condições escolares objetivas, os trabaIhadores-alunos manifestavam dificuldades de dominar a linguagem e a simbologia muito 
distantes das suas realidades familiares, social e laboral, que os levavam a abandonar os estudos, provocando, na maioria das vezes, frustrações e baixa auto-estima.

Captou-se que os trabalhadores-alunos procuraram o curso Técnico em Edificações por terem afinidade com a área de construção civil, aliada à busca pelo crescimento profissional e pessoal. A escolha do curso estaria mais relacionada ao desejo de mudar a posição, ou seja, para promover a transformação social dos trabalhadores-alunos.

Os depoimentos dos alunos vão ao encontro do que foi exposto por Dayrell, (2007, p. 1122), ao afirmar que, em geral, a maioria dos jovens valoriza a escola como "uma promessa futura" pela possibilidade que ela tem de garantir credenciais mínimas capazes de facilitar a inserção no mundo do trabalho. Os sujeitos pesquisados buscaram um caminho inverso do trilhado forçosamente pelas suas trajetórias, que foi "do trabalho para a escola" e não o itinerário da "escola para o trabalho".

O tempo gasto no deslocamento de ônibus entre o trabalho, a escola e a residência além do horário pouco flexível no trabalho, também foram citados como mais uma dificuldade a ser superada. Assim, os trabalhadores-alunos estabeleciam estratégias para vencer a falta de tempo para estudar, aproveitando as viagens de ônibus, os intervalos de almoço no trabalho e os finais de semana. Assim, eles reorganizam sua rotina de conciliação entre trabalho e estudo, estabelecendo estratégias para lidar com as dificuldades que enfrentavam, isto é, driblar as situações desfavoráveis em relação à falta de tempo para estudarem fora da escola.

Diante das referidas dificuldades, os trabalhadores-alunos procuraram meios ou estratégias para minimizar seus problemas escolares, tais como: a definição clara dos horários para estudar; o aumento de atenção às aulas; a "negociação" com os professores para flexibilizar os horários de chegada e saída das aulas; a formação de "pares/amigos" para facilitar a obtenção de informações e materiais para referendar seus estudos; a escolha de locais de assento na sala de aula, mais próximas ou mais distantes do professor.

Os trabalhadores-alunos não gostavam de ser tratados de forma diferenciada, pois muitos professores se sentiam sensibilizados com suas condições e se dispunham a colaborar, detalhando os temas, flexibilizando datas de entrega de trabalhos e os horários de chegada e saída das aulas. Contudo, eles requeriam uma adaptação dos currículos, metodologias e avaliações e recursos às suas necessidades e especificidades.

Em resumo, esses trabalhadores-alunos computavam seus fracassos escolares àtransposição dos projetos e das práticas pedagógicas do turno diurno para o noturno e, também, à insensibilidade de alguns professores para trabalhar com esses alunos.

Dessa forma, alguns alunos sentiam-se desvalorizados, preteridos e, mesmo, excluídos em relação aos alunos de outros cursos. Em muitos casos alegaram que há falta de sintonia entre a administração da escola e os alunos do noturno, podendo significar a existência de uma classificação, uma categorização e diferenciação entre a cultura escolar no interior das instituições. Além disso, criticaram a gestão, administração da escola, que os atendiam de forma meio negligente e discriminatória. 
O grande desafio para os alunos, nessa situação, era superar suas deficiências, obter resultados escolares satisfatórios e permanecer na instituição, apesar das suas dificuldades em conciliar o trabalho com os estudos. Nesse contexto, a qualidade do ensino é prejudicada por afastar o trabalhador-aluno da escola, por ela não atender às suas demandas, provocando a desmotivação e a auto-exclusão.

Reitera-se que essa situação de precarização pode gerar o estresse, o cansaço e o adoecimento, além de provocar sentimentos de auto culpabilização pelo fracasso escolar. Todavia, pode levar a uma automotivação, por provocar nos trabalhadores-alunos a necessidade de gerenciar suas vidas, no sentido de "correrem atrás" de seus objetivos e sonhos. Muitos alunos declararam em suas falas que a escola no período da noite não foi concebida para eles, que não são os "alvos originais da instituição escolar", por vivenciarem irregularidades em suas trajetórias acadêmicas. A escola parece, então, ser realmente um não lugar para esses sujeitos.

Essas descobertas corroboram com a opinião de Leão (1998, p. 1), quando afirma que a escola tem sido incapaz de atender o aluno do noturno em sua totalidade, na globalidade de sua vida fora da escola, reconhecendo os sentimentos vividos no trabalho, na cidade e na família. Para esse pesquisador, "a experiência da escola noturna pelos alunos-trabalhadores caracteriza-se pelo estranhamento, pelo não lugar."

Logo, a discussão sobre os limites e possibilidades impõe o dever de discutir as condições para que, dentro do processo ensino-aprendizagem, o aluno da escola noturna, esteja ele iniciando suas atividades no mundo do trabalho ou já inserido nele, possa construir sua aprendizagem com significado, para que ela seja a base de sua vida, progredindo verticalmente rumo ao ensino superior ou permanecendo no mesmo nível secundário, com melhores condições de sucesso profissional.

As turmas se peculiarizavam por certo nível de diversidade, acentuadamente quanto à idade, pois uns eram jovens e outros já mais amadurecidos. Em decorrência, ocorreram alguns conflitos de interesses e posicionamentos que acabaram interferindo negativamente no relacionamento entre os alunos. As turmas nas quais os trabalhadores-alunos estudavam caracterizavam-se pela heterogeneidade de idade e objetivos, consubstanciada nas faixas etárias, nas visões de mundo, níveis de aprendizagem e objetivos. Essas diferenças trouxeram desdobramentos específicos, como o fato de alguns alunos conseguirem ter bons desempenhos e outros não conseguiam avançar, entre outros, por não terem clareza do que objetivavam fazer após a conclusão do curso profissionalizante de nível médio.

Percebe-se entre os trabalhadores-alunos uma fragilidade na relação com a escola, provavelmente decorrente da dificuldade de conciliar o trabalho com o estudo, o que dificulta a administração de suas rotinas diante do acúmulo de atividades laborais e estudantis. A jornada de 40 horas semanais ou mais dedicadas ao trabalho pode representar um fator de risco, prejudicando e contribuindo para o baixo rendimento escolar e a consequente evasão escolar. A combinação do trabalho intenso com os estudos pode ser penosa e provocar 
sobrecarga emocional, estresse e adoecimento. A difícil permanência dos alunos pôde ser minimizada pela concessão de bolsas estudantis, de alimentação e de transporte.

Os vínculos da relação com a escola são frágeis na relação dos alunos, mas os trabalhadores-alunos viam a escola como um espaço de convivência social, onde construíram relações de amizades que os motivaram a aumentar suas frequências nas aulas. Alguns desses estudantes muitas vezes sentiam desconforto por estarem em descompasso escolar, tendo eles a concepção de que sua qualificação é inferior à dos demais colegas, por possuírem pouca escolarização e idade não compatível com o ensino médio.

A maioria dos trabalhadores-alunos declarou sua intenção de prosseguir nos estudos após a conclusão do curso técnico, mesmo reconhecendo suas realidades impactadas pelas suas condições de trabalhadores. Consequentemente, esses sujeitos se esforçaram para conciliar o trabalho com o estudo, pois visualizavam na possibilidade da conclusão do curso técnico a viabilização para a inserção nos setores laboral e social, em níveis mais altos. Assim, a obtenção de um diploma/certificado de técnico se tornaria um passaporte na sociedade e no mundo laboral.

Nos depoimentos, os trabalhadores-alunos afirmaram que tiveram de alterar seus posicionamentos iniciais a partir da construção e apropriação de estratégias de adaptação às regras, às linguagens, símbolos e aos rituais privilegiados pelas instituições escolares. Assim, perceberam que existem diferenças entre o ambiente escolar e o vivido na vida familiar e no trabalho, pois os códigos e símbolos e a cultura são bem diferentes.

Os trabalhadores-alunos interpretavam a escola como espaço privilegiado de aprendizagem de conhecimentos gerais técnicos mais elaborados, que aumenta sua compreensão de como se organizam os mundos educacionais e laborais, muito distantes do seu cotidiano, como trabalhadores-alunos. E essa conscientização acabou gerando tensões e desafios que precisavam ser superados.

A última categoria final está relacionada ao tempo despendido entre o trabalho e a escola. Segundo os trabalhadores-alunos, a distância do trajeto a ser percorrido também compromete a conciliação entre o trabalho e o estudo, pois esse tempo foi considerado como perdido e exaustivo, diminuindo a possibilidade de se dedicarem mais aos estudos. Esse tempo demorado para a locomoção pode causar desmotivação e impossibilidade de se aplicar mais aos estudos.

Embora as sínteses apresentadas sejam parciais e limitadas aos recortes desta pesquisa, as evidências empíricas permitem confirmar a hipótese e respaldar a tese de que a permanência, em ambos os ambientes, trabalho/escola, não deve ser vista como distante e separada, ao ponto de eles perceberem o trabalho como sendo real, presente e tangível e a escola como um mundo surreal e fictício. Essa situação levou os trabalhadores-alunos a se voltarem mais para o ambiente laboral, preterindo-os e os afastando da escola, pois o trabalho atendia às suas necessidades imediatas, enquanto o estudo se constituía como uma possibilidade não concreta e distante. 
Portanto, a dualização entre a oferta do ensino diurno para privilegiados e a oferta para os "desvalidos da sorte" que frequentam o ensino noturno respalda a histórica diferenciação entre a educação destinada à elite e a voltada para as camadas sociais marginalizadas. Ao se comparar nas duas instituições, os currículos, as infraestruturas, sobretudo dos laboratórios e oficinas, a qualificação dos professores se assemelhava, em contrapartida, as especificidades e realidades dos alunos do noturno nos loci de investigação não eram levadas em consideração.

A real compreensão das características e peculiaridades, facilidades e dificuldades que os trabalhadores-alunos historicamente têm vivenciado, buscando conhecer e atender a seus perfis pessoal, estudantil e laboral, pode possibilitar a elaboração de políticas públicas voltadas para ampliar o nível de qualidade da educação a eles destinada, especialmente no âmbito da RFEPCT.

É preciso minimizar a tradicional tensão e distância entre o que dispõe a legislação e a retórica governamental e suas aplicações reais na concretude dos turnos noturnos, voltados para os trabalhadores-alunos. Contudo, o dualismo educacional, presente na longa trajetória da educação brasileira, somente poderá ser extinto quando ocorrer a real equalização social, capaz de extinguir as grandes desigualdades sociais e econômicas existentes no país.

Nesse sentido, o que se espera é que os resultados desta pesquisa possam indicar novas perspectivas para as políticas públicas voltadas para o trabalhador-aluno, que possam viabilizar reflexões no âmbito dos governantes, também no meio acadêmico e empresarial, no sentido de promover ações voltadas para a criação de melhores oportunidades para esses cidadãos.

Tomar o ensino profissionalizante noturno um debate é um grande desafio, mas em outra conjuntura política pode definir novas políticas que contribuirão para propiciar melhores condições de estudo, compatíveis com suas condições objetivas e necessidades.

Finalmente, considera-se que a pesquisa de campo, levantou e analisou muitas questões que envolviam os trabalhadores-alunos, sobretudo a referente à dificuldade de conciliação entre as duas jornadas, consubstanciadas no estudo e no trabalho. Considerase que a pesquisa qualitativa realizada, pela sua amplitude e profundidade, pode contribuir tanto para diminuir a carência de produções a respeito do ensino noturno, quanto para desvelar as dificuldades enfrentadas pelos trabalhadores-alunos e as suas sagas para conseguirem conciliar estudo e trabalho.

Assim, as instituições pesquisadas vêm recebendo no ensino noturno profissionalizante uma clientela de alunos com históricos marcados por reprovações sucessivas e/ou de abandono da escola. São jovens e adultos oriundos das camadas populares inseridos precariamente no mercado de trabalho ou então dos que têm expectativa de inserção laboral e que buscam no estudo uma nova oportunidade de se escolarizarem para, no futuro, alcançarem melhores condições de sobrevivência, a partir de mais capacitação educacional que viabilize suas inserções profissionais. 


\section{Para Finalizar}

Sem dúvida, a técnica da Análise de Conteúdo, no âmbito da pesquisa qualitativa é uma das mais promissoras, quando associada a procedimentos consistentemente construídos teoricamente. Trata-se de uma técnica bastante abrangente e eficaz, como o estudo aqui aposto mostra, desde que utilizada de forma sistemática e rigorosa.

Como foi verificado no estudo, a Análise de Conteúdo constitui-se por um conjunto de etapas, exigindo do pesquisador embasamento teórico e metodológico antes de lançar-se a campo. O material da coleta de dados, em especial o roteiro de entrevista, deve estar em consonância com os objetivos do estudo, pois, caso contrário, as interpretações e as inferências não serão fiéis ao escopo do trabalho do pesquisador e vazias de sentidos acerca das falas dos sujeitos da pesquisa.

Ressalta-se que a desenvoltura para o uso da Análise de Conteúdo no conjunto de procedimentos metodológicos vai se construindo no decorrer do próprio processo de investigação, pois, por mais que se conheçam as suas exigências, o investigador deve ser capaz de solucionar imprevistos, propósitos e questões com as quais vai se deparando no desenrolar da investigação. A partir dessa perspectiva, a Análise de Conteúdo pode se constituir, também, como uma técnica de análise de dados importante, para o desenvolvimento de novos estudos, contanto que seja aplicada, no âmbito de uma proposta de investigação consistentemente qualificada, desde suas perguntas, objetivos e referenciais teórico e metodológico.

Muito embora enfatiza-se que uma das peculiaridades deste estudo se traduziu no fato de ser um estudo de casos múltiplos, portanto, os resultados aqui apresentados não podem ser generalizados, uma vez que refletem apenas a realidade das instituições estudadas.

Sob a mirada de outros pesquisadores, outros resultados podem surgir. Ademais, a pesquisa qualitativa realizada com os recursos da Análise de Conteúdo ampliou e aprofundou a análise, podendo servir de referência para outros estudos.

Por fim, considera-se que a carência de produções acadêmicas sobre a técnica da Análise de Conteúdo em pesquisas educacionais, a sistematização, a apresentação minuciosa das suas etapas e o rigor conferido à sua aplicação podem fazer deste artigo referência para outras investigações. 


\section{REFERÊNCIAS}

BARDIN, L. Análise de conteúdo. Tradução de Luis Antero Reto e Augusto Pinheiro. São Paulo: Edições 70, 2011.

BOURDIEU, P. CHAMBOREDON, J. PASSERON, J. Ofício de sociólogo, metodologia da pesquisa na sociologia. Tradução de Guilherme João de Freitas Teixeira. 6. ed. Petrópolis, RJ. Ed. Vozes, 2007.

CAIRES, V. G.; OLIVEIRA, M. A. M. Educação profissional brasileira: da colônia ao PNE 20142024. 1. ed., Petrópolis: Vozes, v. 1, 2016. 204 p.

DAYRELL, Juarez. A escola "faz" as juventudes? Reflexões em torno da socialização juvenil. Educação e Sociedade, Campinas, v. 28, n. 100 - Especial, p. 1105-1128, out. 2007. Disponível em: <http://www.scielo.br/pdf/es/v28n100/ a2228100.pdf>. Acesso em: 12 ago. 2018.

GONZÁLEZ REY, F. L. Sujeito e subjetividade: uma aproximação histórico-cultural. São Paulo: Thomson-Pioneira, 2003.

GONZALÉZ REY, F. L. Pesquisa qualitativa e subjetividade. São Paulo: Editora Cengage Learning, 2005.

GODOY, A. S. Refletindo sobre critérios de qualidade da pesquisa qualitativa. Gestão Organizacional, Pernambuco, v. 3, n. 2, mai./ago. 2005. Disponível em: http://www.revista.ufpe.br/gestaoorg/ index.php/gestao/article/viewFile/136/118. Acesso em: set, 2014.

HADDAD, Sérgio. Estado e educação de adultos (1964/1985). 1991. 360 f. Tese (Doutorado) Faculdade de Educação da Universidade de São Paulo. São Paulo. Programa de Pós-Graduação em Educação, 1991.

LEÃO, G. M. P. A gestão da escola noturna: ainda um desafio político. In: REUNIÃO ANUAL DA ANPED, 21, Caxambu. Anais..., Caxambu, 1998. Disponível em: <http://forumeja.org.br/gt18/files/ LEAO.pdf_9.pdf>. Acesso em: 14 jun. 2018.

LUDKE, M; ANDRÉ, M. E. D. A. Pesquisa em educação: abordagens qualitativas. São Paulo: EPU, 1986.

OLIVEIRA, E. de; ENS, R. T.; FREIRE, A. D.; MUSSIS, C. R. de. Análise de conteúdo e pesquisa na área da educação. Revista Diálogo Educacional, vol. 4, núm. 9, maio-agosto, 2003, pp. 1-17.

PARAISO, M. A. Pesquisas pós-críticas em educação no Brasil: esboço de um mapa. Cadernos de Pesquisa, v.34, n. 122, p. 283-303, mai/ago. 2004.

PIRES, A. P. Políticas Públicas para o Ensino Noturno: um estudo sobre os trabalhadores-alunos de duas instituições da RFEPCT. 2017. 296 f. Tese (Doutorado). Pontifícia Universidade Católica de Minas Gerais, Programa de Pós-Graduação em Educação. Belo Horizonte, 2017.

ROCHA, G., TOSTA, S. P. (orgs.). Construindo metodologias de pesquisa em Educação e Antropologia. Curitiba: CRV, 2013. 
TENCA. Sueli Cotrim. Cursos noturnos: a pobre escolarização dos que trabalham. Caderno de Pesquisa. São Paulo, n. 43, p. 37-41, nov. 1982. Disponível em: http://publicacoes.fcc.org.br/ojs/index.php/ cp/article/view/1556. Acesso em: 13 dez. 2013.

TOGNI, Ana Cecília; CARVALHO, Marie Jane Soares. A escola noturna de ensino médio no Brasil. OEI - Revista Iberoamericana de Educación, n.44, maio-ago. 2007. Disponível em:<http://www. rieoei.org/rie44a04.htm>. Acesso em: 9 jul. 2018.

TOSTA, S. P.Os usos de etnografia na pesquisa educacional. Relatório de pesquisa. Belo Horizonte: PUC-Minas, 2005.

TOSTA, S. P.Sobre a pesquisa em Educação: apontamentos. Texto de aula. Belo Horizonte: PUC-Minas; PPG-Educação, 2016.

VOSGERAU, D. S. R., POCRIFKA, VOSGERAU, D. S. R.Etapas da análise de conteúdo complementadas por ciclos decodificação: possibilidades a partir do uso e software de análise quantitativa dedados. In: $5^{\circ}$ Congresso Ibero-americano de Investigação Qualitativa, 2016, p. 789-798. 